\title{
A Probable Relationship between Physical Exercise and COVID-19 Mediated by the Renin-Angiotensin-Aldosterone System
}

\author{
Renato Aparecido de Souza, ${ }^{1,2}$ Priscila Missaki Nakamura, ${ }^{1,3}$ Inaian Pignatti Teixeira, ${ }^{4}{ }^{\circledR}$ Marco Tulio de Souza, ${ }^{5}$ \\ Wonder Passoni Higino ${ }^{1,2}$ (1) \\ Federal Institute of Education, Science and Technology of South of Minas Gerais - Campus Muzambinho, ${ }^{1}$ Muzambinho, MG - Brazil. \\ Federal University of Alfenas, ${ }^{2}$ Postgraduate Program in Rehabilitation Science, Alfenas, MG - Brazil. \\ São Paulo State University - Institute of Biosciences, Campus Rio Claro, ${ }^{3}$ Rio Claro, SP - Brazil \\ University of São Paulo, ${ }^{4}$ School of Arts, Sciences and Humanities, São Paulo, SP - Brazil \\ Campinas Medical Center Hospital, ${ }^{5}$ Campinas, SP - Brazil
}

At the end of 2019, a novel human virus (SARS-CoV-2) causing severe acute respiratory syndrome (SARS) expanded globally from China. In February 2020, the World Health Organization (WHO) officially named this infectious disease coronavirus disease 2019 (COVID-19), and in March 2020, WHO announced COVID-19 a global pandemic. In June 2020, according to an interactive web-based dashboard to track COVID-19 in real time developed by the Johns Hopkins University Center for Systems Science and Engineering (https://www.eficiens. com/coronavirus-statistics/), more than 7 million people infected with the new coronavirus and more than 400,000 deaths were confirmed around the world. ${ }^{1}$ China and European countries have found solutions to manage and reduce the number of daily infections. However, new COVID-19 cases have risen at alarming rates in many other countries, and today Brazil is the third country in number of cases. ${ }^{2}$

Recently, angiotensin-converting enzyme 2 (ACE2) was identified as an entry receptor for SARS-CoV-2. The binding of the novel coronavirus to ACE2 can reduce (downregulation) the number of ACE2 receptors, causing severe damage to alveolar cells that triggers a series of pulmonary and respiratory reactions that can lead to death. ${ }^{3,4}$

ACE2 is part of a complex and integrated metabolic pathway known as the renin-angiotensin-aldosterone

\section{Keywords}

COVID-19; Betacoronavirus; SARS-CoV2; Severe Acute Respiratory Syndrome; Pandemics; ReninAngiotensin System; Exercise/prevention and control. system (RAAS), which has been the target of several studies that describe physiological adaptations induced by physical exercise. Thus, given the potential role of ACE2 in the pathophysiology of coronavirus infection, this scientific letter sought to establish a probable relationship between physical exercise and COVID-19 through the RAAS and thereby add a contribution to studies on the management and prevention of COVID-19.

\section{The Pathways of the RAAS}

The classical pathway of the RAAS is initiated by the release of angiotensinogen by the liver, which, combined with renin secreted by the kidneys, produces angiotensin I (Angio I). Angio I is converted to angiotensin II (Angio II) by the action of the angiotensin-converting enzyme (ACE) in the lungs. The physiological effects of Angio II are mediated primarily through membrane receptors, especially of the Angio II type 1 (AT1) receptor. These receptors, when stimulated, promote vasoconstriction, hypertrophy and hyperplasia of vascular cells, sodium retention, generation of reactive oxygen species (ROS), and inflammatory, thrombotic and fibrotic processes, which can cause tissue damage. ${ }^{5}$

A counter-regulatory pathway of the RAAS involves the conversion of Angio II to angiotensin 1-7 (Angio-1-7) and membrane receptors (MAS) through the enzymatic activity of angiotensin-converting enzyme 2 (ACE2), which promotes a vasodilatory, anti-inflammatory, antifibrotic, and anti-proliferative effect on the tissues. ${ }^{6}$ Under appropriate physiological conditions, there is a balance between these two RAAS pathways (Figure 1).

Mailing Address: Renato de Souza

Rua Dinah, 75, Canaã. Postal Code: 37890-000, Muzambinho, MG - Brazil.

E-mail: renato.souza@muz.ifsuldeminas.edu.br 


\section{Physical Exercise and the RAAS}

Previous studies, especially experimental studies, have shown that physical exercise can reduce the activation of the classic RAS pathway and increase the activation of the components of the counter-regulatory pathway (ACE2/Angio-1-7/MAS) (Figure 2). ${ }^{7-13}$

However, the literature is still scarce about the effects of physical exercise on the ACE2/Angio-1-7/ MAS pathway, mainly on ACE2 (the primary receptor site of SARS-CoV-2). In short, it was shown in rodents that physical exercise increased the expression of MAS receptors in aortas, thereby improving the vasodilatory effect of Angio-1-7. ${ }^{9}$ Deficiency of ACE2 has been shown to be related to impaired physical performance and adaptations of the cardiac and skeletal muscles. ${ }^{10}$ In addition, swimming improved oxidative capacity ${ }^{11}$ and sensitivity to insulin in muscle tissue ${ }^{12}$ and in all these studies, a role of the ACE2/Angio-1-7/MAS pathway has been suggested to be involved in the adaptive process. In humans, it was shown that aerobic physical exercise acutely increased the activity of the ACE2/Angio-1-7/ MAS pathway, leading to increased plasma and urinary levels of ACE2, especially with a continuous moderate exercise protocol. ${ }^{13}$
In addition, evidence from genetic studies have shown the relationship between physical exercise and RAAS modulation. Among the main findings, it has been highlighted that physical exercise affects the cardiovascular system, by lowering blood pressure, inhibiting the interactions between ACE, Angio II, and AT1 receptors activated by the classical RAAS pathway, and increasing the expression of ACE2. ${ }^{14,15}$

\section{COVID-19 and Physical Exercise}

The lethality of COVID-19 has been associated with a decrease in the number of ACE2 receptors, impairing the activation of this important lung-protective protection pathway., ${ }^{3,4}$ With less ACE2 available to convert Angio II to Angio-1-7, preventing the anti-inflammatory and anti-fibrotic effects of the ACE2/ Ang-(1-7)/Mas pathway, more angiotensin is produced via the ACE/Ang-I/AT1 pathway, leading to a heightened inflammatory milieu and lung damage. ${ }^{16}$

With respect to therapeutic research on COVID-19, at least three clinical approaches targeting ACE2 receptors have been described: vaccines, Angio II receptor blockers, and by increasing the levels of the soluble form of ACE2. ${ }^{4}$

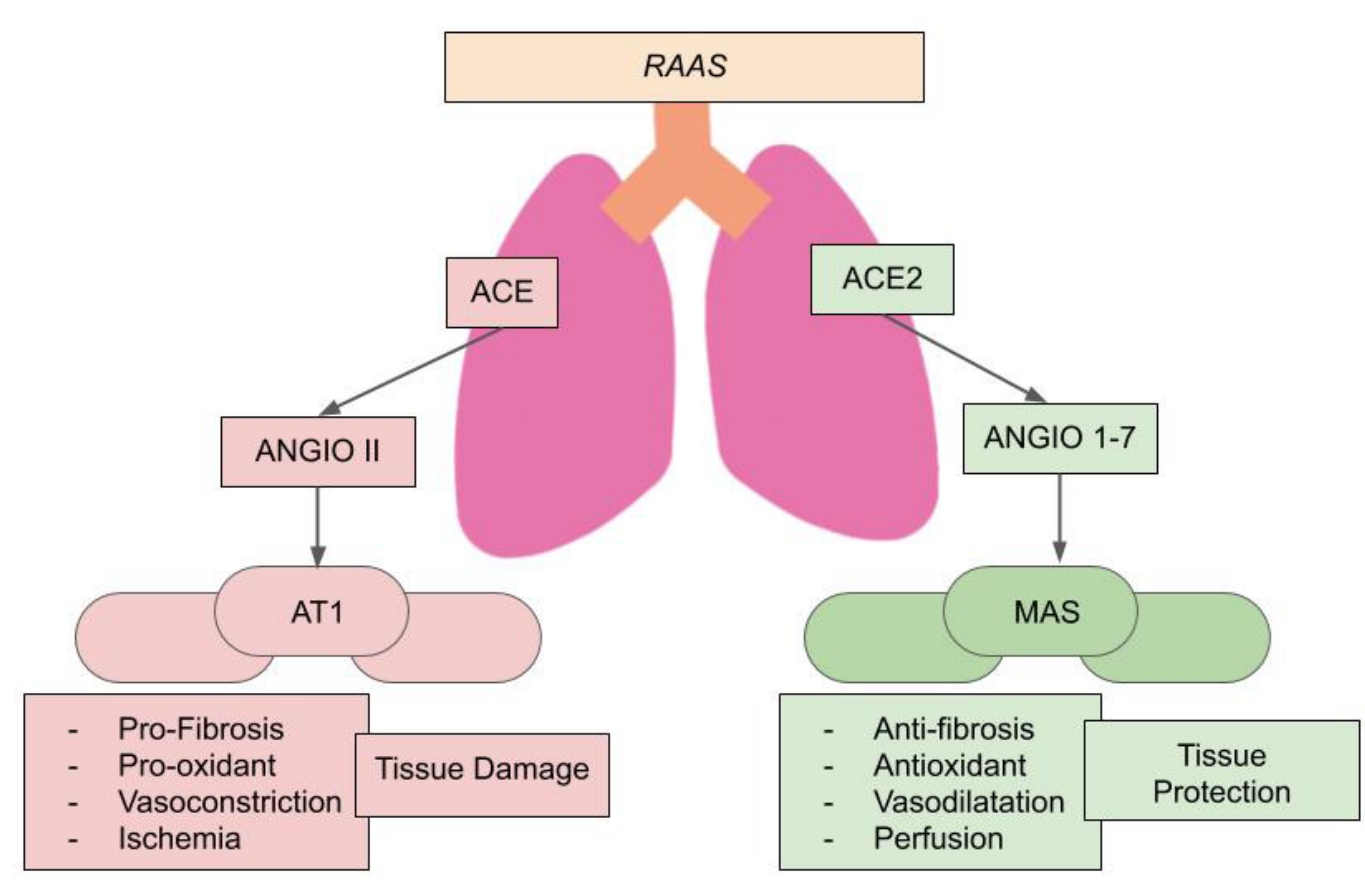

Figure 1 - Balance between the two pathways of the renin-angiotensin-aldosterone system (RAAS) and their general effects. Classical pathway: ACE: Angiotensin-converting enzyme; ANGIO II: Angiotensin II; AT1: Membrane receptors for Angio II; Counter-regulatory pathway: ACE2: Angiotensin-converting enzyme 2; ANGIO 1-7: Angiotensin 1-7; MAS: Membrane receptors for Angio 1-7. 


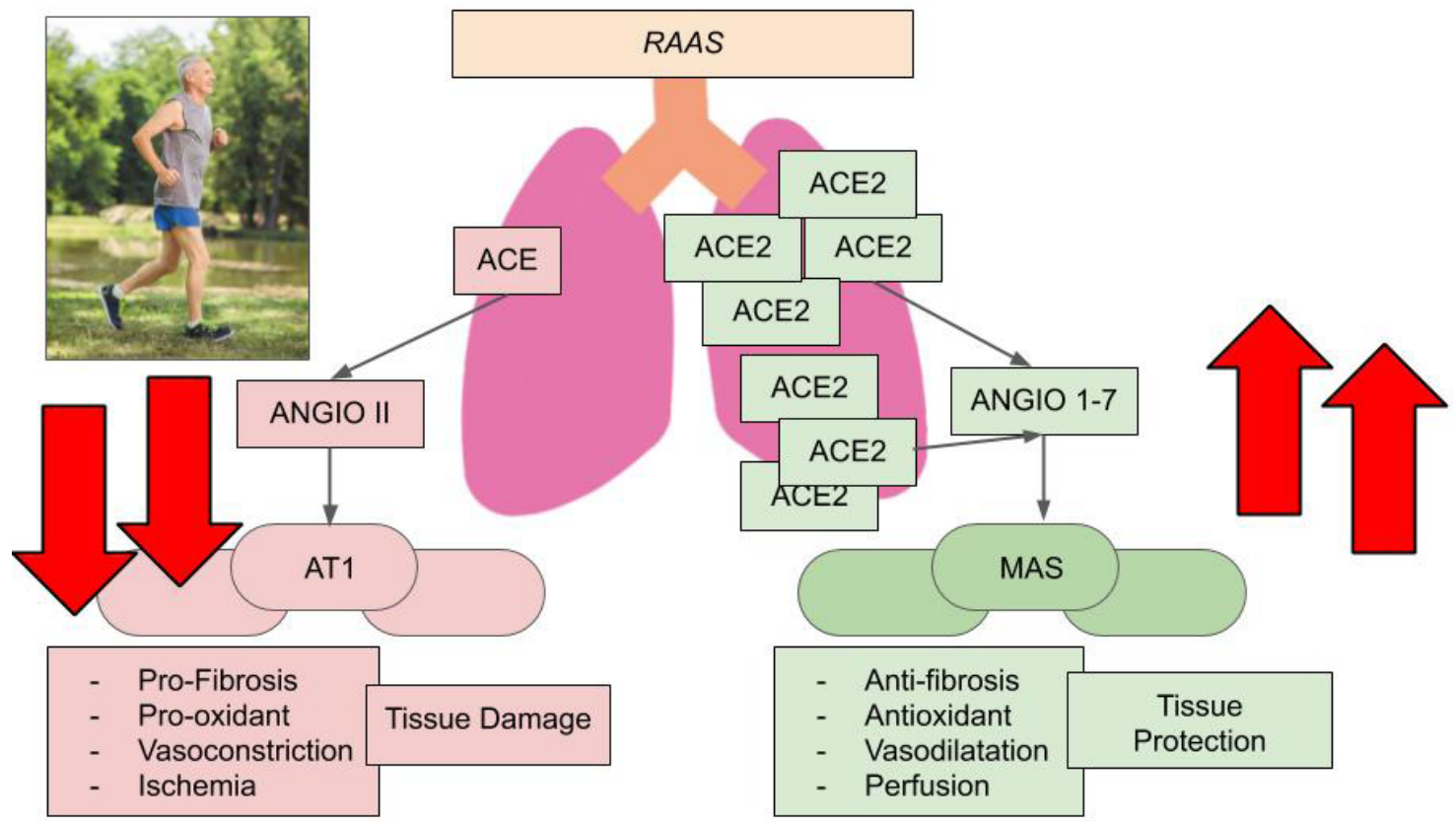

Figure 2 - Possible effect of physical exercise on the two pathways of the renin-angiotensin-aldosterone system (RAAS); classical pathway: ACE: Angiotensin-converting enzyme; ANGIO II: Angiotensin II; AT1: Membrane receptors for Angio II; Counter-regulatory pathway: ACE2: Angiotensin-converting enzyme 2; ANGIO 1-7: Angiotensin 1-7; MAS: Membrane receptors for Angio 1-7. Down arrows indicate downregulation and decreased activation. Up arrows indicate upregulation and increased activation.

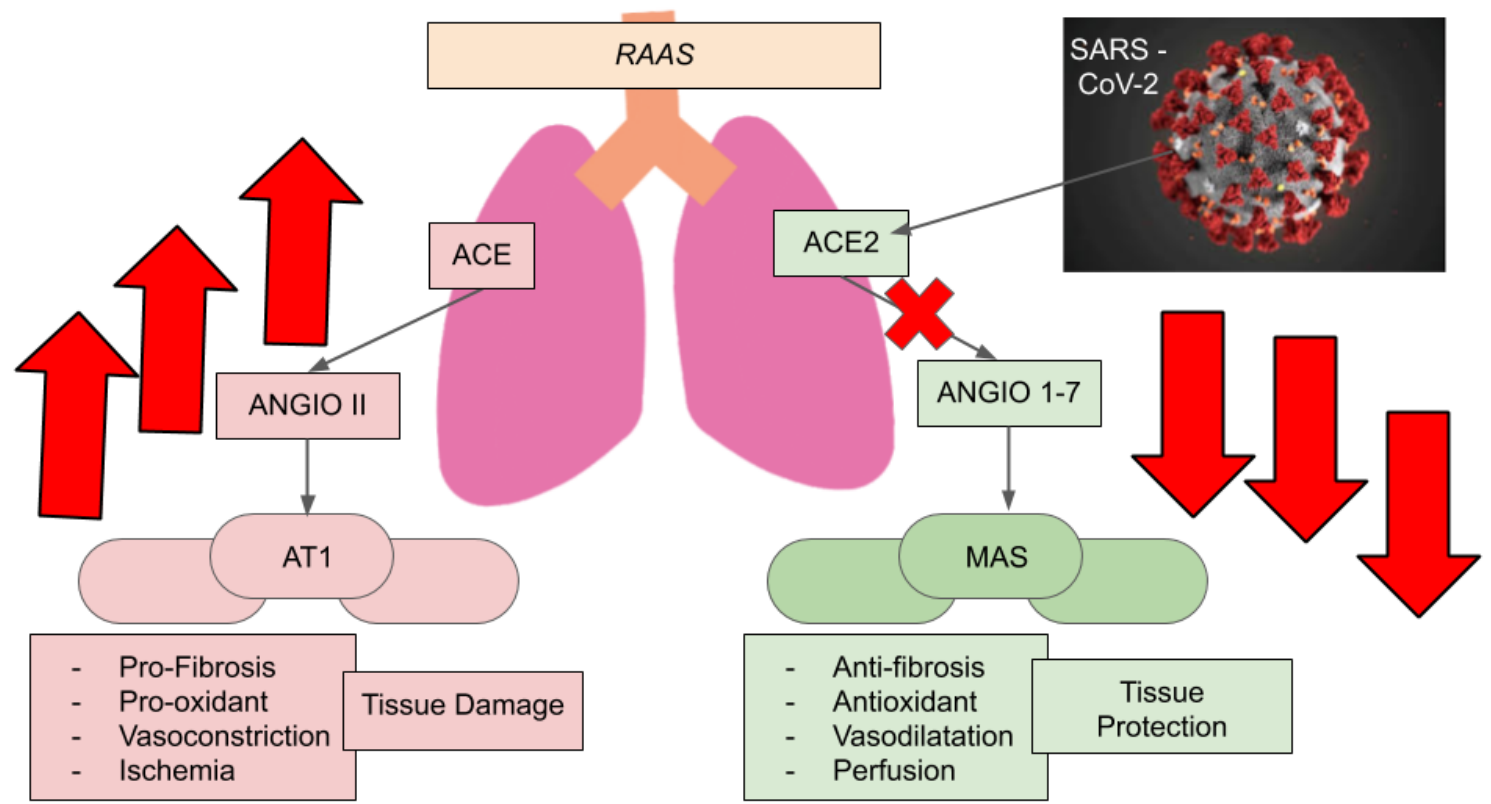

Figure 3 - Effect of coronavirus disease-2019 (COVID-19) on the two pathways of the renin-angiotensin-aldosterone system (RAAS); classical pathway: ACE: Angiotensin-converting enzyme; ANGIO II: Angiotensin II; AT1: Membrane receptors for Angio II; Counterregulatory pathway: ACE2: Angiotensin-converting enzyme 2 (receptor site for the new coronavirus); ANGIO 1-7: Angiotensin 1-7; MAS: Membrane receptors for Angio 1-7. Down arrows indicate downregulation and decreased activation; up arrows indicate upregulation and increased activation. 
This last strategy has been suggested based on the fact that soluble ACE2 could prevent the binding of the coronavirus to the full-length ACE2, and thereby not only neutralize the virus but also rescue ACE2 cellular activity, counterregulating RAAS and protecting pulmonary tissue. ${ }^{17}$

Thus, based on the above, the potential link between physical exercise and COVID-19 is the following: while the new coronavirus is capable of compromising the ACE2/Angio-1-7/MAS pathway (Figure 3), physical exercise would be able to stimulate it, and hence prevent the RAAS imbalance and associated lung injury. ${ }^{18}$

In addition, considering that (I) chronic diseases, such as diabetes, obesity, dyslipidemia and hypertension, are important risk factors that increase the lethality of COVID-19, (ii) the elderly population is the group with the highest COVID-19 mortality rates, ${ }^{3}$ (iii) the aging process reduces the expression of ACE2, and the classical pathway of RAAS is involved in the pathophysiology of many chronic diseases, and that (iv) there is scientific evidence supporting the benefits of regular physical exercise for the elderly population and people with chronic non-transmissible diseases, ${ }^{19,20}$ a protective effect of physical exercise against the effects of COVID-19 may be suggested.

However, until now, there has been no scientific study evaluating the preventive effects of exercise on COVID-19 or studies with patients with COVID-19 submitted to physical exercise. In fact, the American College of Sports Medicine (ACSM) recently published a brief position recommending that people exercise during the COVID-19 pandemic. $^{21}$

Given the scientific basis presented here, it seems reasonable to consider a protective effect of physical exercise in relation to COVID-19, by restoring or maintaining an appropriate balance between the classical and counter-regulatory pathways of the RAAS. Future studies are needed to clarify the relationship between physical exercise and COVID-19. For now, in addition to the widespread use of preventive measures, such as the correct hand washing, use of gel alcohol and face masks, and social isolation/distancing, physical exercise should also be considered for COVID-19 prevention.

\section{Author Contributions}

Conception and design of the research: Souza RA, Nakamura PM, Teixeira IP, Souza MT, Passoni WH. Analysis and interpretation of the data: Souza RA, Nakamura PM, Teixeira IP, Souza MT, Passoni WH. Writing of the manuscript: Souza RA, Nakamura PM, Teixeira IP, Souza MT, Passoni WH. Critical revision of the manuscript for intellectual content: Souza RA, Nakamura PM, Teixeira IP, Souza MT, Passoni WH.

\section{Ethics approval and consent to participate}

This article does not contain any studies with human participants or animals performed by any of the authors.

\section{Potential Conflict of Interest}

No potential conflict of interest relevant to this article was reported.

\section{Sources of Funding}

There were no external funding sources for this study.

\section{Study Association}

This study is not associated with any thesis or dissertation work.

\section{References}

1. Coronavirus Statistics Number of Cases [Internet]. Coronavirus interactive real-time dashboard - outbreak evolution. [citado em 05 jun. 2020]. Disponível em: https://www.coronavirus-statistiques.com/ stats-globale/coronavirus-number-of-cases/.

2. Menezes PL, Garner DM, Valenti VE. Brazil is projected to be the next global covid19 pandemic epicenter. MedRxiv. 2020;

3. Lu R, Zhao X, Li J, Niu P, Yang B, Wu H, et al. Genomic characterisation and epidemiology of 2019 novel coronavirus: implications for virus origins and receptor binding. Lancet. 2020;395(10224):565-74.

4. Zhang H, Penninger JM, Li Y, Zhong N, Slutsky AS. Angiotensin-converting enzyme 2 (ACE2) as a SARS-CoV-2 receptor: molecular mechanisms and potential therapeutic target. Intensive Care Med. 2020; 46(4):586-90.

5. Williams B. Drug discovery in renin-angiotensin system intervention: past and future. Ther Adv Cardiovasc Dis. 2016; 10(3):118-25.

6. Santos RAS, Sampaio WO, Alzamora AC, Motta-Santos D, Alenina N, Bader $\mathrm{M}$, et al. The ACE2/angiotensin-(1-7)/MAS Axis of the renin-angiotensin system: focus on angiotensin-(1-7). Physiol Rev. 2018; 98(1):505-53.

7. Frantz EDC, Prodel E, Braz ID, Giori IG, Bargut TCL, Magliano DC, et al. Modulation of the renin-angiotensin system in white adipose tissue and skeletal muscle: focus on exercise training. Clin Sci (Lond). 2018; 132(14):1487-507.

8. Nunes-Silva A, Rocha GC, Magalhaes DM, Vaz LN, Salviano de Faria MH, Simões e Silva AC. Physical exercise and ACE2-angiotensin-(1-7)-mas receptor axis of the renin angiotensin system. Protein Pept Lett. 2017; 24(9):809-16.

9. Silva DMR, Gomes-Filho A, Olivon VC, Santos TM, Becker LK, Santos RAS, et al. Swimming training improves the vasodilator effect of angiotensin-(1-7) in the aorta of spontaneously hypertensive rat. J Appl Physiol. 2011; 111(5):1272-7. 
10. Motta-Santos D, Dos Santos RA, Oliveira M, Qadri F, Poglitsch M, Mosienko V, et al. Effects of ACE2 deficiency on physical performance and physiological adaptations of cardiac and skeletal muscle to exercise. Hypertens Res. 2016; 39(7):506-12.

11. Soares DDS, Pinto GH, Lopes A, Caetano DSL, Nascimento TG, Andrades $\mathrm{ME}$, et al. Cardiac hypertrophy in mice submitted to a swimming protocol: influence of training volume and intensity on myocardial renin-angiotensin system. Am J Physiol Regul Integr Comp Physiol. 2019; 316(6):R776-R782

12. Echeverría-Rodríguez O, Gallardo-Ortíz IA, Del Valle-Mondragón L, VillalobosMolina R. Angiotensin-(1-7) Participates in Enhanced Skeletal Muscle Insulin Sensitivity After a Bout of Exercise. J Endocr Soc. 2020; 4(2):1-11, bvaa007

13. Magalhães DM, Nunes-Silva A, Rocha GC, Vaz LN, de Faria MHS, Vieira ELM, et al. Two protocols of aerobic exercise modulate the counter-regulatory axis of the reninangiotensin system. Heliyon. 2020; 6(1):e03208.

14. Domingo R, Sturrock ED, Collins M. ACE activity and endurance performance during the South African Ironman triathlons. Int J Sports Med. 2013; 34(5):402-8.
15. Cam S, Colakoglu M, Colakoglu S, Sekuri C, Berdeli A. ACE I/D gene polymorphism and aerobic endurance development in response to training in a non-elite female cohort. J Sports Med Phys Fitness. 2007; 47(2):234-8.

16. Kuba K, Imai Y, Penninger JM. Angiotensin-converting enzyme 2 in lung diseases. Curr Opin Pharmacol. 2006; 6(3):271-6.

17. Yu L, Yuan K, Ai Phuong HT, Park BM, Kim SH. Angiotensin-(1-5), an active mediator of renin-angiotensin system, stimulates ANP secretion via Mas receptor. Peptides. 2016; 86:33-41.

18. Gurwitz D. Angiotensin receptor blockers as tentative SARS-CoV-2 therapeutics. Drug Dev Res. 2020;81(5):537-40.

19. Stefani L, Galanti G. Physical Exercise Prescription in Metabolic Chronic Disease. Adv Exp Med Biol. 2017; 1005:123-41.

20. Wahid A, Manek N, Nichols M, Kelly P, Foster C, Webster P, et al. Quantifying the Association Between Physical Activity and Cardiovascular Disease and Diabetes: A Systematic Review and MetaAnalysis. J Am Heart Assoc. 2016; 5(9): e002495.

21. The American College of Sports Medicine (ACSM). Staying Physically Active During the COVID-19 Pandemic. [Internet]. 2020 [acesso em 2020 mar 23]. Disponível em: https://www.acsm.org/read-research/newsroom/ news-releases/newsdetail/2020/03/16/staying-physically-active-duringcovid-19-pandemic. 